\title{
Beta-Human Chorionic Gonadotropin and Uterine Artery Doppler Measurements for the Prediction of Success of Single Dose Methotrexate Treatment in Tubal Ectopic Pregnancies
}

\author{
Çiğdem KILIÇ¹, Mehmet Metin ALTAY ${ }^{1}$, Tuğba KINAY ${ }^{1}$, Metin KAPLAN ${ }^{1}$, Serap FIRTINA TUNCER ${ }^{1}$ \\ Enis ÖZKAYA², Ahmet Okyar EROL'1, Orhan GELIŞEN' ${ }^{1}$
}

Ankara, Turkey

\begin{abstract}
OBJECTIVES: To evaluate the impact of the uterine artery Doppler values and the change of $\beta$-Human chorionic gonadotropin ( $\beta-\mathrm{HCG}$ ) levels from day 0 to day 4 for prediction of the success of single dose methotrexate treatment in tubal pregnancy cases.

STUDY DESIGN: 50 patients with tubal pregnancy were included the prospective study. The location and size of ectopic pregnancy, bilateral uterine artery pulsed color doppler imaging was examined by ultrasonography and serum $\beta-$ HCG levels were measured on day $0,4,7$ of treatment. Success was defined as decrease of $\beta-\mathrm{HCG}$ level $<10 \mathrm{mlU} / \mathrm{mL}$ with single dose methotrexate treatment. Multiple dose methotrexate treatment and surgical treatment were considered as treatment failure.
\end{abstract}

RESULTS: 32 patients (64\%) treated with single dose methotrexate, 14 patients $(28 \%)$ treated with multiple dose methotrexate, and 4 patients $(8 \%)$ treated with surgery. In the group with $\beta-\mathrm{HCG}$ level decrease $>15.04 \%$ on day 4 , single-dose methotrexate therapy were 3.82 times more successful than the group without $>15.04 \% \beta$-HCG decrease. However, no significant alteration of uterine artery Doppler measurements was determined on the same days.

CONCLUSION: Reduction rate in the $\beta$-HCG level on day 4 of treatment can be used in determination the success of single-dose methotrexate therapy.

Keywords: $\beta$-Human chorionic gonadotropin, Ectopic pregnancy, Methotrexate, Single dose, Uterine artery Doppler

Gynecol Obstet Reprod Med 2016;22:22-26

\section{Introduction}

Ectopic pregnancy is defined as an implantation of the fertilized ovum outside the uterus, often the fallopian tubes. ${ }^{1}$ Compared to previous years; the incidence of ectopic pregnancy was increased depending on the induction of ovulation, tubal sterilization and increased incidence of pelvic infection. ${ }^{2}$ Early diagnosis by the sensitive Human Chorionic Gonadotropin (HCG) measurements, transvaginal ultrasonography, and widespread use of laparoscopic surgical procedures

${ }^{1}$ Etlik Zübeyde Hanım Women's Health Training and Research Hospital, Ankara

2 Zeynep Kamil Women's and Children Health Training and Research Hospital, Ankara

Address of Correspondence: Tuğba Kınay

Department of Obstetrics and

Gynecology, Etlik Zubeyde Hanm

Women's Health Training and Research

Hospital Etlik, Ankara, Turkey

tkinay@hotmail.com

Submitted for Publication:

18. 08.2015

Accepted for Publication:

22. 10.2015 play a considerable role in the increased incidence of ectopic pregnancy. ${ }^{3}$ Surgical treatment of ectopic pregnancy is still used all over the world as the definitive treatment method. Methotrexate is an alternative treatment method to surgery in selected patients. Medical management of unruptured ectopic pregnancy has many advantages; such as low cost, reduced risk of tubal damage and consequent increase in fertility potential. ${ }^{4-6}$

Success of single-dose methotrexate treatment is evaluated according to changes in the serum HCG levels. A>15\% decrease in HCG levels from day 4 to day 7 of treatment shows treatment success. According to the classical knowledge, the change in the level of HCG between 0 and 4 days is not important in the assessment of treatment failure.

In a normal pregnancy blood flow resistance decrease progressively in the uterine arteries, and increased uterine artery blood flow, decreased pulsality index (PI) and resistance index (RI) are detected by Doppler ultrasonography examination. In the literature, there are several studies determining blood flow resistance, in the abnormal pregnancies. ${ }^{7-9}$ However, there is no study investigating association between uterine artery 
Doppler findings and success of ectopic pregnancy treatment. The purpose of this study was to investigate the effect of the changes in the level of HCG from day 0 to day 4 and uterine artery Doppler values for the prediction the success of single dose methotrexate treatment in patients with tubal pregnancy.

\section{Material and Method}

Fifty tubal ectopic pregnancy cases were included in the prospective study. The study was approved by the local instutional review board. Informed consent was obtained from all patients prior to their inclusion in the study. Patients were evaluated by medical and surgical history, physical and gynecological examination, pregnancy testing, ultrasonography, and endometrial sampling. Patients with $<4 \mathrm{~cm}$ tubal pregnancy were hemodinamically stable, had no evidence of rupture and contraindication for methotrexate treatment. A single dose of methotrexate was administered intramuscularly at a dose of $50 \mathrm{mg}$ per square meters of body surface. $\beta$-HCG levels, complete blood count, liver and renal function tests were evaluated in all patients prior to treatment. $\beta$-HCG levels were reassessed on day 4 and 7 of treatment.

Patients with deteriorating hemodynamics, significant pain symptom and rebound tenderness during follow-up underwent surgical treatment. Patients whose $\beta$-HCG levels decrease less than $15 \%$ from day 4 to day 7 were given an additional dose of methotrexate and it was considered treatment failure.

The location and size of ectopic pregnancy, bilateral uterine artery pulsed color Doppler imaging was examined by ultrasonography on day 0,4 , and 7 of treatment. All sonographic measurements were performed via transvaginal route, using 6$10 \mathrm{MHz}$ multifrequency endovaginal probe (Logiq P5, GE Healthcare Inc., Milwaukee, Wisconsin, USA). All uterine artery Doppler measurements were performed by one examiner. The peak systolic and end-diastolic flow velocity, resistance index (RI), pulsatility index (PI), and systolic / diastolic (S / $\mathrm{D})$ ratio of the right and left uterine artery were calculated.

Statistical analysis was performed using SPSS 15.0 (SPSS
Inc., Chicago, IL, USA) for Windows package program. The descriptive statistics were presented mean values and standard deviation or median (min-max) for continous variables, and frequency and percent for categorical variables. Student's t test or Mann Whitney U test were used for comparison of continuous data. Logistic regression analysis was used to evaluate the effect of decrease rates in $\beta$-HCG levels on the outcome of single dose methotrexate treatment. Statistical significance was considered as $\mathrm{p}<0.05$.

\section{Results}

Fifty patients between the ages of 23 and 45 were included the study. $18 \%$ of patients $<25$ years of age, $66 \%$ of the $25-35$ age, and $16 \%$ were $>35$ years of age. The mean number of pregnancies was 3 (min $1-\max 8)$; the mean number of births was 1 ( $\min 0$-max 3 ). Forty-five patients $(90 \%)$ conceived spontaneously, 5 patients $(10 \%)$ conceived with intrauterine insemination. The mean duration of pregnancy was $45.04 \pm 12.56$ days. Pretreatment $\beta$-HCG was minimum $29 \mathrm{mI} / \mathrm{mL}$, maximum $16022 \mathrm{mIU} / \mathrm{mL}$, the median value was $549 \mathrm{mIU} / \mathrm{mL}$.

While $3(6 \%)$ patients had no symptoms at admission, 30 patients $(60 \%)$ had vaginal bleeding, 5 patients $(10 \%)$ had pelvic pain, and 12 patients $(24 \%)$ had both pelvic pain and vaginal bleeding. Existing risk factors for ectopic pregnancy in the study group are shown in Table 1.

Four patients $(8 \%)$ were treated with surgery, 14 patients $(28 \%)$ were treated with multiple- dose methotrexate therapy, and 32 patients $(64 \%)$ were treated with single-dose methotrexate. Median initial $\beta$-hCG level was $387 \mathrm{mIU} / \mathrm{mL}$ (minimum 29 - maximum 3015) in patients treated with single-dose methotrexate, and $1585 \mathrm{mIU} / \mathrm{mL}$ (minimum 139maximum 16022) in patients treated with multiple doses of methotrexate or undergoing surgery due to rupture of tubal pregnancy $(\mathrm{p}<0.001)$.

The rate of patients with $>15.04 \%$ decrease in $\beta$-HCG levels on day 0 to 4 was significantly higher in the single-dose methotrexate group compared to the surgical treatment and

Table 1: Distribution of risk factors for ectopic pregnancy in the study group

\begin{tabular}{lccc}
\hline Risk Factors & Present $\mathrm{n}(\%)$ & Absent $\mathrm{n}(\%)$ & Total $\mathrm{n}(\%)$ \\
\hline Previous ectopic pregnancy & $8(16)$ & $42(84)$ & $50(100)$ \\
Previous tubal surgery & $2(4)$ & $48(96)$ & $50(100)$ \\
Use of intrauterine device & $7(14)$ & $43(86)$ & $50(100)$ \\
History of infertility & $7(14)$ & $43(86)$ & $50(100)$ \\
History of pelvic infection & $7(14)$ & $43(86)$ & $50(100)$ \\
Previous abdominal surgery & $16(32)$ & $34(68)$ & $50(100)$ \\
Cigarette smoking & $21(42)$ & $29(58)$ & $50(100)$ \\
Vaginal douching & $4(8)$ & $46(92)$ & $50(100)$ \\
\hline
\end{tabular}


multiple-dose methotrexate group (65.6\% versus $33.3 \%$, p $<0.05)$. As a result of the ROC analysis; the calculated threshold of percentage change between day 0 and day 4 was 15.04\% (Figure 1).

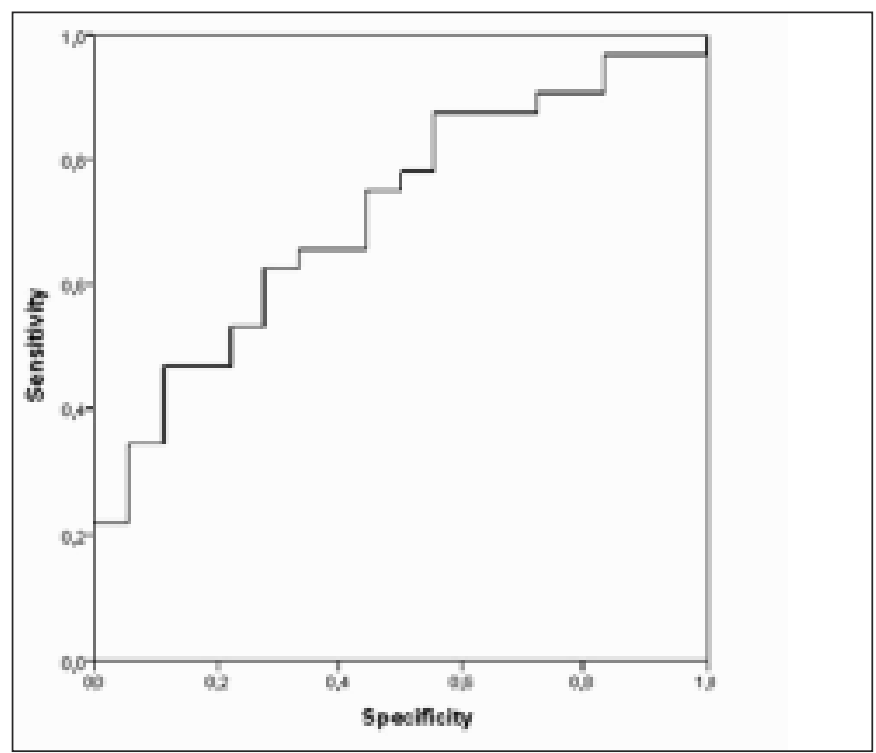

Figure 1: Receiver operating characteristic (ROC) curve for $\beta$ $H C G$ in prediction of the success of single dose methotrexate treatment
In patients whose $\beta$-HCG levels decreased less than $15.04 \%$ on day 4 compared with baseline day, there were 3.82 times more risk for taking multiple-doses of methotrexate or undergoing to surgery (95\% CI 1.13-12.95; $\mathrm{p}<0.05)$. This calculated threshold value had a sensitivity of $78 \%$, specificity of $52 \%$, positive predictive value of $66 \%$, negative predictive value of $44 \%$ in determining the success of treatment.

Uterine artery Doppler values on days 0, 4 and 7 in patients treated with single dose methotrexate was presented in Table 2. While changes in the bilateral uterine artery pulsality index and resistance index were not different between days 0 and 4 of single-dose methotrexate therapy, changes in the right and left uterine artery systolic / diastolic ratio between days 0 and 4 were significantly different $(\mathrm{p}<0.05)$. However, we did not find a cutoff value for systolic/ diastolic ratio as a result of the ROC analysis. There was also no significant difference in the uterine artery Doppler values between the ipsilateral side of ectopic pregnancy and the contralateral side $(\mathrm{p}>0.05)$ (Table 3$)$.

\section{Discussion}

Ectopic pregnancy continues to be one of the important topics of obstetric and gynecology because of the $10 \%$ maternal mortality rate. For this reason, there has been important

Table 2: Uterine artery Doppler values on days 0, 4 and 7 in patients with tubal pregnancy treated with single dose methotrexate

\begin{tabular}{|c|c|c|c|c|c|c|}
\hline \multirow[t]{2}{*}{ Uterine Artery Doppler Values } & \multirow{2}{*}{$\begin{array}{c}\text { Day } 0 \\
\text { Mean } \pm \\
\text { SD }\end{array}$} & \multirow{2}{*}{$\begin{array}{c}\text { Day } 4 \\
\text { Mean } \pm \\
\text { SD }\end{array}$} & \multirow{2}{*}{$\begin{array}{c}\text { Day } 7 \\
\text { Mean } \pm \\
\text { SD }\end{array}$} & \multicolumn{3}{|c|}{$P$ values } \\
\hline & & & & $\begin{array}{c}\text { Day 0- } \\
\text { Day } 4\end{array}$ & $\begin{array}{c}\text { Day 0- } \\
\text { Day } 7\end{array}$ & $\begin{array}{c}\text { Day 4- } \\
\text { Day } 7\end{array}$ \\
\hline Pulsatility Index (Right) & $2.13 \pm 0.52$ & $2.22 \pm 0.48$ & $2.28 \pm 0.52$ & $>0.05$ & $>0.05$ & $>0.05$ \\
\hline Resistance Index (Right) & $0.81 \pm 0.08$ & $0.88 \pm 0.38$ & $0.83 \pm 0.06$ & $>0.05$ & $>0.05$ & $>0.05$ \\
\hline Systole / Diastole Ratio (Right) & $5.82 \pm 1.52$ & $6.77 \pm 2.09$ & $6.39 \pm 1.77$ & $<0.01$ & $>0.05$ & $>0.05$ \\
\hline Pulsatility Index (Left) & $2.06 \pm 0.58$ & $2.22 \pm 0.44$ & $2.35 \pm 1.12$ & $>0.05$ & $>0.05$ & $>0.05$ \\
\hline Resistance Index (Left) & $0.81 \pm 0.07$ & $0.83 \pm 0.05$ & $0.83 \pm 0.07$ & $>0.05$ & $>0.05$ & $>0.05$ \\
\hline Systole / Diastole Ratio (Left) & $5.61 \pm 1.60$ & $6.50 \pm 1.69$ & $6.68 \pm 2.56$ & $<0.01$ & $<0.01$ & $>0.05$ \\
\hline
\end{tabular}

Table 3: Uterine artery Doppler values of the ipsilateral and contralateral side of ectopic pregnancy on days 0,4 and 7 in patients treated with single dose methotrexate

\begin{tabular}{lllll}
\hline Uterine Artery Doppler Values & & Day 0 & Day 4 & Mean \pm SD \\
Pulsatility Index & & $2.11 \pm 0.53$ & $\begin{array}{c}\text { Day } 7 \\
\text { Mean } \pm \text { SD }\end{array}$ \\
\hline Resistance Index & Ipsilateral & $2.08 \pm 0.57$ & $2.26 \pm 0.45$ & $2.37 \pm 1.10$ \\
& Contralateral & $0.81 \pm 0.08$ & $2.17 \pm 0.46$ & $2.26 \pm 0.56$ \\
Systole / Diastole Ratio & Ipsilateral & $0.81 \pm 0.08$ & $0.83 \pm 0.06$ & $0.82 \pm 0.06$ \\
& Contralateral & $5.72 \pm 1.46$ & $0.89 \pm 0.38$ & $0.83 \pm 0.07$ \\
& Ipsilateral & $5.71 \pm 1.66$ & $6.67 \pm 1.92$ & $6.58 \pm 2.30$ \\
\hline
\end{tabular}

$P>0.05$ 
progress in the diagnosis and treatment of ectopic pregnancy and maternal mortality rates have decreased in the last 20 years. Despite a decrease in mortality rates, incidence of ectopic pregnancy increased due to increased incidence of pelvic inflammatory disease and developments in the treatment of infertility. ${ }^{2}$

In a study including 254 patients, ectopic pregnancy risk factors and treatment options were reported. Twelve percent of patients had history of pelvic surgery, $6 \%$ of patients had history of ectopic pregnancy, $6 \%$ of patients had history of intrauterine device use, $5.5 \%$ of patients had history of infertility, and $4 \%$ of patients had history of pelvic inflammatory disease. ${ }^{10}$ In our study, these rates were higher. While $32 \%$ of patients had history of previous abdominal surgery, $4 \%$ of patients had history of previous tubal surgery, $16 \%$ of patients had previous ectopic pregnancy, $14 \%$ of patients had use of the IUD, $14 \%$ of patients had infertility, and $14 \%$ of patients had history of pelvic inflammatory disease.

Sagiv and colleagues'11 found that initial $\beta$-HCG levels were important in determining the effectiveness of treatment. They claimed that $\beta$-HCG levels less than $2000 \mathrm{mIU} / \mathrm{L}$ before treatment may determine the success of treatment with a single dose of methotrexate. Nowak-Markwitz et al. ${ }^{12}$ study in 2009 showed the doses of methotrexate treatment were not determined in patients with $\beta$-hCG level $>1700 \mathrm{mlU} / \mathrm{mL}$; but a single dose of the methotrexate treatment was sufficient in patients with $\beta$-HCG level is between 1218-1790 mIU/L. Similarly, we found that the initial $\beta$-hCG levels were lower in patients treated with single dose methotrexate successfully.

Change in $\beta$-HCG level is important in determining the success of methotrexate treatment. As reported in the literature; less than $15 \%$ decrease in $\beta$-HCG levels from day 4 to 7 requires an additional dose of methotrexate. Our study showed that if $\beta$-HCG levels decrease at least $15.04 \%$ from day 0 to day 4 , single dose methotrexate is sufficient in these patients. This cut-off value is useful to determine the patients who will not require a second dose methotrexate earlier, and may shorten the duration of hospital stay. In our study; patients with $<15.04 \%$ reduction in $\beta$-HCG levels on day 4 were 3.82 times more needed additional dose of methotrexate or underwent surgical treatment.

Szabo and colleagues' ${ }^{13}$ explored the alteration in uterine artery Doppler values in 49 patients with early tubal ectopic pregnancy. Unlike our study; they have found a significant reduction in uterine artery pulsality index and resistance index values. Roshan Agarwal et al. ${ }^{14}$ was found initial uterine artery Doppler values and serum $\beta$-HCG levels were effective in determining the prognosis of treatment in patients with gestational trophoblastic neoplasia. However, there was no study investigating the association between uterine artery Doppler values and the success of methotrexate treatment in ectopic pregnancy. In our study, we evaluated the impact of uterine artery
Doppler measurements in determining the success of treatment in tubal pregnancy cases treated with single dose methotrexate. There was no significant change in bilateral mean pulsality and resistance indices between the days 0,4 and 7 in patients treated with a single dose methotrexate successfully; but there was statistically significant change of mean systolic / diastolic ratio between days 0 and 4 . However, as a result of ROC analysis, we did not find a cut-off value for mean systolic / diastolic ratio. We also did not find any significant difference in the uterine artery Doppler values between the ipsilateral side of ectopic pregnancy and the contralateral side.

In conclusion; at least $15.04 \%$ reduction in $\beta$-HCG levels on day 4 suggests that the single-dose methotrexate treatment alone may be sufficient. However, uterine artery Doppler values on days 0,4 , and 7 for determinining the success of single dose methotrexate treatment was not found to be useful.

\section{References}

1. Ory SJ. New options for diagnosis and treatment of ectopic pregnancy. JAMA 1992;267:534-7.

2. Hallatt JG. Repeat ectopic pregnancy: a study of 123 consecutive cases. Obstet Gynecol 1975;45:542-4.

3. Chow WH, Daling JR, CatesW Jr, Greenberg RS. Epidemiology of ectopic pregnancy. Epidemiol Rev 1987;9:70-94.

4. Schoen JA, Nowak RJ. Repeat ectopic pregnancy: a 16year clinical survey. Obstet Gynecol 1975;45:542-6.

5. Levin AA, Schoenbaum SC, Stubblefield PG, Zimicki S, Monson RR, Ryan KJ. Ectopic pregnancy and prior induced abortion. Am J Public Health 1982;72:253-6.

6. Glock JL, Johnson JV, Brumsted JR. Efficacy and safety of single-dose systemic methotrexate in the treatment of ectopic pregnancy. Fertil Steril 1994;62:716-21.

7. Kurjak A, Zudenigo D, Funduk-Kurjak B, Shalan H, Predanic M, Sosic A. Transvaginal color Doppler in the assessment of the uteroplacental circulation in normal early pregnancy. J Perinat Med 1993;21:25-34.

8. Kurjak A, Zalud I, Salihagic A, Crvenkovic G, Matijevic R. Transvaginal color Doppler in the assessment of abnormal early pregnancy. J Perinat Med 1991;19:155-65.

9. Kurjak A, Zalud I, Predanic M, Kupesic S. Transvaginal color and pulsed Doppler study of uterine blood flow in the first and early second trimesters of pregnancy: normal versus abnormal. J Ultrasound Med 1994;13:43-7.

10. Kazandi M, and Turan V. Ectopic pregnancy; risk factors and comparison of intervention success rates in tubal ectopic pregnancy. Clin Exp Obstet Gynecol 2011;38:67-70.

11. Sagiv R, Debby A, Feit H, Cohen-Sacher B, Keidar R, Golan A. The optimal cutoff serum level of human chorionic gonadotropin for efficacy of methotrexate treatment in women with extrauterine pregnancy. Int J Gynaecol 
Obstet 2012;116:101-4.

12. Nowak-Markwitz E, Michalak M, Olejnik M, Spaczynski M. Cutoff value of human chorionic gonadotropin in relation to the number of methotrexate cycles in the successful treatment of ectopic pregnancy. Fertil Steril 2009; 92:1203-7.

13. Szabó I, Csabay L, Belics Z, Fekete T, Papp Z.
Assessment of uterine circulation in ectopic pregnancy by transvaginal color Doppler. Eur J Obstet Gynecol Reprod Biol 2003;10;106:203-8.

14. Agarwal R, Strickland S, McNeish IA, et al. Doppler ultrasonography of the uterine artery and the response to chemotherapy in patients with gestational trophoblastic tumors.Clin Cancer Res 2002;8:1142-7. 